Etnográfica

Revista do Centro em Rede de Investigação em

Antropologia

vol. $24(2) \mid 2020$

Vol. $24(2)$

\title{
La equivocación de un territorio en conflicto: experiencias y narrativas qom en el sur del Gran Chaco
}

The equivocation of a territory in conflict: Qom experiences and narratives in south of Gran Chaco

\section{Pedro Emilio Robledo}

\section{(2) OpenEdition}

\section{Journals}

\section{Edición electrónica}

URL: https://journals.openedition.org/etnografica/9147

DOI: 10.4000/etnografica.9147

ISSN: 2182-2891

\section{Editor}

Centro em Rede de Investigação em Antropologia

Edición impresa

Fecha de publicación: 1 junio 2020

Paginación: 503-525

ISSN: 0873-6561

\section{Referencia electrónica}

Pedro Emilio Robledo, «La equivocación de un territorio en conflicto: experiencias y narrativas qom en el sur del Gran Chaco», Etnográfica [En línea], vol. 24 (2) | 2020, Publicado el 31 julio 2020, consultado el 21 enero 2022. URL: http://journals.openedition.org/etnografica/9147 ; DOI: https://doi.org/ 10.4000/etnografica.9147

\section{(c) (7) \&}

Etnográfica is licensed under a Creative Commons Attribution-NonCommercial 4.0 International License. 


\section{La equivocación de un territorio en conflicto: experiencias y narrativas qom en el sur del Gran Chaco}

\section{Pedro Emilio Robledo}

Reflexiono sobre la equivocación (sensu Viveiros de Castro) que revela un territorio, ubicado en el Chaco argentino, producto de una reparación histórica estatal que convirtió en propietarios a indígenas qom y en ocupantes ilegales a no indígenas. Grandes áreas deshabitadas, así como la inconstancia de los asentamientos indígenas, refuerzan acusaciones de un uso irracional de este territorio. Estas sospechas contrastan con nociones nativas de poder, posesión y necesidades, nacidas de una interacción sociocósmica en un paisaje habitado por potencias no humanas, que proporcionan parámetros para la convivencia humana en este lugar. Así, la mezquindad y generosidad de humanos y no humanos fundamentan una ocupación del territorio caracterizada por una notable movilidad espacial. Argumento que este desencuentro, antes que una oposición de intereses o un error comunicativo generado por la diferencia cultural, expresa una equivocación. Al tiempo que la cuestión para colonos criollos y agentes estatales es 'cómo aprovechar mejor el territorio', para los qom el problema consiste en saber 'qué lugar es más receptivo a sus pedidos y necesidades'.

PALABRAS ClAVE: Gran Chaco, qom, territorialidad indígena, equivocación, desarrollo, conflictos ontológicos.

The equivocation of a territory in conflict: Qom experiences and narratives in south of Gran Chaco - I reflect on the equivocation (sensu Viveiros de Castro) revealed by a territory, located in argentinean Chaco, a result of an official compensation which has turned Qom indigenous into owners and non-indigenous people into illegal occupants. Large uninhabited areas and the inconstancy of indigenous settlements reinforce accusations of irrational use of this territory. These suspicions constrat with native notions of power, possession and needs, born from a socio-cosmic interaction in a landscape inhabited by non-human powers, provide parameters for human coexistence in this place. Thus, the pettiness and generosity of humans and nonhumans support an occupation of the territory characterized by notable spatial mobility. I argue that this conflict expresses an equivocation rather than an opposition of interests or a communicative error produced by the cultural difference. While the problem for the creole settlers and state agents is "how to make the best use of the territory", for the Qom is "which place is the most receptive to their asks and needs".

KEYWORDS: Gran Chaco, Qom, indigenous territoriality, equivocation, development, ontological conflicts.

ROBLEDO, Pedro Emilio (emiliorobledo10@gmail.com) - Universidad Nacional de Córdoba, Argentina. 


\section{INTRODUCCIÓN}

Las resonantes demandas y reocupaciones de territorios ancestrales promovidas por la movilización de las poblaciones indígenas americanas de fines del siglo pasado, han avivado notablemente el debate social sobre la territorialidad indígena, hecho que ha impactado sensiblemente en la imaginación y reflexión antropológica (Feld y Basso 1996; Ingold 1986; Gupta y Ferguson 1992). Como antropólogo, había oído acerca de un extenso territorio en la región conocido como el bosque Impenetrable chaqueño, en el Chaco argentino, que tras décadas de resistencia indígena (específicamente de los qom) ${ }^{1}$ había sido reconocido como territorio indígena (Centro de Estudios Legales y Sociales 1991). Motivado por conocer en profundidad este caso emblemático de recuperación de tierras por parte de un pueblo indígena, en 2012 emprendí un trabajo de campo etnográfico en la región que se extendió hasta $2016 .^{2}$ Allí, durante tres estadías, que totalizaron seis meses, conviví con mis anfitriones qom y transité junto a ellos gran parte de este territorio conformado por montes, pastizales, lagunas y cambiantes cursos de agua.

Además de la imponente extensión del territorio (150.000 ha continuas), dos cosas llamaron mi atención: la gran concentración de la población en puntos específicos, en torno a los denominados "parajes", ${ }^{3}$ y la inestabilidad que caracterizaba la ocupación y aprovechamiento del área. De hecho, gran parte de las observaciones de las agencias de promoción apuntan a la inconstancia indígena con respecto a los planes de ordenamiento territorial, tanto a nivel productivo como ambiental. En ello también se apoyan las voces críticas de la población criolla que debió ser relocalizada para cumplir con los acuerdos que indican que solo los qom pueden habitar dicho territorio. Todo ello conforma un "sentido común" que se traduce en requerimientos a corregir ese "irracional uso de la tierra". Los cotidianos entredichos a menudo se basan en malos entendidos que, a veces, perturban los canales de diálogo para una convivencia

I Los qom o "tobas" como también se los conoce, viven en la actualidad en zonas rurales y urbanas del Chaco argentino, boliviano y paraguayo. En Argentina además han formado asentamientos en populosas ciudades como Santa Fe, Rosario, La Plata y Buenos Aires. Su lengua denominada qom l'aqtaqa presenta variaciones regionales y un mayor uso en las zonas rurales que en las urbanas. Lingüísticamente, la lengua toba pertenece al grupo de lenguas guaycurúes, entre las que se incluye el caduveo, el mocoví, el pilagá y las extintas mbayá, payaguá y abipón (Lafone Quevedo 1893). Como todos los chaqueños, al momento del contacto con la sociedad colonial, los qom basaban su sustento en la caza-pesca-recolección y se organizaban en grupos de familias extensas con alta movilidad espacial, que suponía alternar diversidad de ecosistemas y fuentes de recursos en el ciclo anual (Braunstein y Miller 1999).

2 Agradezco a las familias del paraje de Olla Quebrada (El Espinillo) por su amabilidad, hospitalidad y conocimientos, sin los cuales este trabajo no podría haber sido escrito.

3 "Paraje" es el nombre que recibe en la región el agrupamiento de residencias rurales, más o menos dispersas, que constituyen lo que en habla hispana se conoce como una localidad. 
pacífica entre indígenas y criollos, y otras tornan inviables los programas de promoción y dificultan el sostenimiento de lo que se consideran políticas de desarrollo de largo plazo. Todo ello genera un clima político y económico inestable. Para los qom, la falta de apoyo a sus necesidades es atribuida a la intención de terceros de afectarlos y justifican así su búsqueda de oportunidades en nuevos lugares, dentro o fuera de su territorio, debiendo a veces abandonar sus viviendas y lotes.

Más que interesarme en la "historia de los indígenas" desde un enfoque que se centre en las relaciones interétnicas, en este texto me interesa ahondar en la "historia indígena" de las relaciones con sus otros (Fausto y Heckenberger 2007). Tal como sostiene Florencia Tola (2016), en esta historia indígena interviene no solo el Estado y la sociedad criolla, sino también diversos existentes no-humanos quienes participan con el estatuto de personas en la socialidad qom (Tola 2010, 2012). Asimismo, dicha historia indígena no se limita a las referencias a acontecimientos de un pasado remoto, sino también de experiencias recientes. En esta historia que se expresa por medio de relatos, recuerdos y sueños, y que guarda continuidad narrativa y conceptual con el tiempo del mito, ${ }^{4}$ encontramos conceptos nativos cuyos supuestos no tienen correspondencia ontológica con aquellos de los que se valen funcionarios, técnicos e incluso antropólogos.

Así, los conceptos de comunidad indígena (en tanto cultura particular), recursos naturales o bosque nativo (en tanto naturaleza universal) y territorio (en tanto naturaleza significada por la cultura) no necesariamente tienen una continuidad ontológica con los conceptos nativos que aluden a esas realidades. Por ejemplo, en la afirmación de mis interlocutores "ne'ena 'aviaq l'enaxat Pianne lma" ", cuya traducción literal sería "ese monte se llama (o es) la casa (o lugar) de Pianne" (Pianne es un existente no-humano, el "dueño" de ese monte), ¿dónde estaría la cultura y dónde la naturaleza? ¿Ese monte sería naturaleza, aunque está siendo controlado por un ser no-humano? ¿Pianne es cultura por ser producto de la imaginación de los qom o es naturaleza por ser parte del monte? ¿Ese monte es territorio de los qom o es de Pianne?

Recurro a la noción de equivocación o equivocidad (Castro 2004, 2010) para abordar los malos entendidos que recorren esta experiencia territorial, en primera instancia, para problematizar la presunción de que ellos se deban a una cuestión lingüística, subjetiva, de comprensión, o una llana apatía culturalmente motivada. En todo caso, lo que habría es una referencia a una alteridad radical a partir de nociones homónimas (monte, persona, sociedad,

4 Como se verá luego, ello no quiere decir que los indígenas vivan en un tiempo paralelo al de la historia de la sociedad dominante o documental, en todo caso la historicidad indígena no separa los acontecimientos míticos, de los acontecimientos generados por la interacción humana precolonial o colonial. Después de todo, desde el punto de vista nativo "lo intercultural no es otra cosa que un caso particular de lo interespecífico, y la historia no es sino una versión del mito" (Castro 2010: 75). 
propiedad, etc.). Sin embargo, no busco elaborar una justificación sofisticada de la actitud indígena para intentar acortar la brecha de los malos entendidos. La equivocación a la que me refiero no alude a una diferencia radical entre el mundo que "ve el Estado" y el mundo "que ven los indígenas", sino a la alteridad radical e irreductible que es el modo en el que aparece el mundo, desde el punto de vista indígena. Transitar ese mundo es equivocar: no hay otra manera de transitar un mundo compuesto por múltiples posiciones perspectivas, donde la persona puede ver y hacer aquello que su cuerpo-natural le posibilita (Castro 1996). En definitiva, en este trabajo no me propongo aclarar los malos entendidos, simplemente pretendo recorrer y describir esas tentativas de traducciones y comparaciones que implican la equivocación, desde el punto de vista qom. Quizás esto nos aproxime más adecuadamente al conflicto que se desenvuelve en este lugar.

\section{TERRITORIO INDÍGENA, DESARROLLO E HISTORIA}

La región del Impenetrable chaqueño, que abarca el noroeste de la provincia de Chaco, el este de Salta y el suroeste de Formosa, es un bosque semiárido que incluye montes de xerófilas, sabana, humedales y ríos de cursos cambiantes. Es llamada así por la densidad de su vegetación y escasez de agua, características que han dificultado durante siglos su exploración y colonización por parte del Estado y de la población criolla. Sin embargo, los diversos grupos indígenas chaqueños, valiéndose de una alta movilidad, han aprovechado desde siempre esta región como territorios de caza, pesca, meleo y recolección de frutos, hojas, raíces y más tarde como refugio de las avanzadas militares de fines de siglo XIX. Desde entonces, dichos grupos han tenido que convivir con la sedentarización forzada, la evangelización, la práctica agrícola, el asalariamiento de su fuerza de trabajo y la afluencia de ganaderos criollos. Siendo una región marginal para los intereses del capital agroindustrial de la época, se convirtió en receptora de grupos indígenas desplazados desde otras zonas. En este contexto se desarrollaron las reducciones, reservas y misiones indígenas, dispositivos encargados de la contención y formación de dicha población para su eventual integración a la economía y sociedad nacional - Cordeu y Siffredi (1971); Iñigo Carrera (2010); Niklison (1916); Trinchero, Piccinini y Gordillo (1992) -.

Este ha sido el caso de la reserva indígena Teuco, ubicada en el noroeste de la actual provincia de Chaco, fundada en 1924 a partir de 150.000 ha destinadas por el Gobierno nacional para el asentamiento y sustento de los qom de la zona y de los desplazados hacia allí. La falta de una administración idónea y de límites claros de la reserva configuraron normas laxas que permitieron a la población indígena organizar en gran medida su vida y asentamiento en base a estrategias propias, pero también posibilitó que ganaderos criollos y obrajeros aprovecharan los recursos de la reserva para sus fines. Hacia mediados de 
siglo $\mathrm{xx}$, los organismos estatales dedicados a la integración de los indígenas (v.g. Dirección Provincial del Aborigen) se hicieron más presentes y retomaron la administración de la reserva a partir de políticas que procuraron promover la economía indígena en base a la pequeña producción agraria. Como consecuencia se mensuraron unas 10.000 ha y se entregaron títulos de propiedad individual a un conjunto de familias qom para incentivar esta nueva economía indígena. ${ }^{5}$ La idea era que ello sirviera de modelo para el resto de la población de la reserva, pero las chacras no prosperaron y el plan decayó.

Hacia fines del siglo XX, renovadas ideas de desarrollo basadas en la sustentabilidad del medio ambiente y la participación de las poblaciones locales, sumado al auge del reconocimiento nacional e internacional de los derechos territoriales y culturales indígenas, ${ }^{6}$ se convirtieron en las bases para las nuevas políticas destinadas a la Reserva. Pero esta vez estuvieron encabezadas por agencias de promoción gubernamentales y no gubernamentales nacionales e internacionales, con la participación de las nacientes organizaciones indígenas. ${ }^{7}$ En este marco, la alianza de estos actores con líderes qom sostuvo con éxito el reclamo por el reconocimiento de las restantes 140.000 ha que formaban parte de la reserva, pero que no habían sido mensuradas hasta el momento. Para ese entonces, este sector ya venía siendo aprovechado durante décadas por ganaderos criollos y obrajeros, por lo cual debió llegarse a un acuerdo de reordenamiento territorial y relocalización de la población no indígena. En este caso, la forma jurídica que se escogió para dar entidad jurídica al territorio indígena fue la propiedad comunitaria. ${ }^{8}$

5 Siguiendo las presunciones nacionales que entienden a la familia nuclear (padres e hijos) como la unidad social a partir de la cual se conforma el Estado, estos programas de desarrollo rural contemplaron como unidad doméstica, es decir la unidad productiva y de consumo, destinataria de sus políticas a dicho agrupamiento, la familia nuclear. Así, toda pareja adulta con hijos a cargo dispuesta a asentarse en un área escogida como piloto, fue considerada beneficiaria del programa y acreedora de 50 hectáreas. Por supuesto que este tipo de políticas debe entenderse en el marco del proceso de incorporación de la población indígena a la sociedad nacional. Lo cual tuvo consecuencias, entre otros aspectos, en la forma de residencia familiar, dando protagonismo a la familia nuclear y restándoselo a la familia extendida, la que constituía la unidad social de la sociedad qom previa al contacto (para un caso toba similar al que aquí se expone, $c f$. Cordeu 1967).

6 Como el Convenio 169 de la Organización Internacional del Trabajo sobre pueblos indígenas y tribales de 1989 y la reforma constitucional de la República Argentina de 1994.

7 Por ejemplo, el Proyecto de Desarrollo Integrado Interfluvio Teuco-Bermejito estuvo a cargo del gobierno provincial del Chaco y ONG locales y contó con fondos de la Comisión Federal de Inversiones y de la Unión Europea. Por su parte, el Proyecto Bosques Tropicales fue financiado por la Unión Europea e implementado por la ONG Volens de Bélgica.

8 Cabe aclarar que en la coyuntura política esta estrategia fue la más adecuada, ya que mensurar y titularizar un solo lote era menos costoso que mensurar y titularizar varios individuales. Por otro lado, la legislación nacional e internacional favorecía el reconocimiento de los territorios indígenas, pero para eso exigía la conformación de la "comunidad indígena" como entidad jurídica. Véase por ejemplo la ley nacional 23.302 cuando en sus arts. 2, 3, 4 estipula que tipo asociación y relación entre sus [continua] 
He hecho hincapié en los programas de desarrollo porque estos han sido elementos centrales de las políticas públicas (gubernamentales y no gubernamentales) en los últimos 50 años, donde la noción de desarrollo se ha presentado de múltiples formas, pero siempre como una solución racional y sopesada a los problemas de la pobreza. A este respecto, el debate antropológico de las últimas décadas ha mostrado que el "desarrollo", lejos de ser un mero curso ascendente del bienestar de las sociedades, resulta un producto de la relación entre metrópolis coloniales y colonias, o bien entre los actuales países centrales y los periféricos (Escobar 1999; Viola 2000). Se podría decir que el par "desarrollo-subdesarrollo" exacerba una discontinuidad entre el estado social de una sociedad y otra, al ver sus características económicas, sociales y políticas como cualidades intrínsecas e independientes de sus relaciones pasadas con otras, cuando tal disociación no existe en el transcurso de las tentativas de convergencia de las sociedades denominadas subdesarrolladas, ni existió en el nacimiento de las llamadas desarrolladas. De hecho, lo que hay siempre es una interdependencia entre estos polos. Esto es lo que ha sido notablemente expuesto por Marx (2012) en su estudio de la "acumulación originaria" capitalista, la cual no podría entenderse ni lógica ni históricamente sin el colonialismo, concretamente, queda de manifiesto que el desarrollo de la industrialización no ha sido un fenómeno autónomo, sino un producto indirecto de la relación histórica entre Occidente y las sociedades primitivas colonizadas.

Por ello hablar del "desarrollo" es hablar, no solo de "políticas de desarrollo" " , sino también de la historia de la modernidad occidental, la cual no puede ser pensada aislada del encuentro entre el mundo europeo y americano. Muchas veces se ha pasado por alto que Claude Lévi-Strauss (1973) ha adherido a la tesis marxista y ha abordado el análisis del desarrollo en tanto historia, donde cuestiona las tesis según las cuales el desarrollo es una función simple y unidireccional del impacto de una cultura más compleja y activa sobre otra más simple y pasiva. Resulta relevante incorporar al debate al fundador de la antropología estructural, ya que, al distinguir entre sociedades frías y calientes, Lévi-Strauss (1988) incorpora no una distinción de naturaleza entre sociedades que tendrían historia y otras que no, sino la posibilidad de que haya diversas historicidades, esto es diferentes actitudes subjetivas hacia la historia. Ello es lo que permite pensar que la historicidad indígena no transcurre al margen de la historia de la modernidad occidental, prueba de ello es que "la apertura al otro" y "la transformación", en tanto conceptos de la mitología

[continuación] miembros se entenderán como "comunidad indígena" y cómo deberá refrendarse y regirse la misma. Asimismo, en su art. 7 establece en qué condiciones se reconocerán y titularizará la tierra a favor de las "comunidades indígenas".

9 En el sentido que, por ejemplo, Jacques Rancière (2004) le da a "la política" en tanto instrumentalización de los acuerdos establecidos para vivir en sociedad. 
amerindia, no impiden al mundo indígena pensar su relación con el mundo no indígena (Lévi-Strauss 1995). Dicho esto, revisemos en el caso en análisis cómo se presenta la historicidad indígena en relación al desarrollo, en tanto historia reciente.

\section{LOS QOM VIVEN EN LOS PARAJES}

En cuestión de una centuria, los qom han pasado de practicar una ocupación territorial dispersa y con una alta movilidad que les permitía alternar diversas zonas en el ciclo anual, a vivir en asentamientos relativamente estables con una creciente participación de la planificación productiva y urbana gubernamental. Ello ha dado como resultado el "paraje", un agrupamiento más o menos disperso de viviendas localizadas en áreas rurales, asociadas a montes o cursos de agua circundantes. ${ }^{10}$ En el territorio qom cada paraje posee un nombre - casi siempre en lengua qom y en castellano - por el que es reconocido, y por lo general cuenta con una iglesia (evangélica) que congrega a las familias del mismo, un establecimiento de educación primaria y algún tipo de personería jurídica por medio de la cual los "dirigentes" locales (líderes que colaboran con los representantes políticos de algún partido local) representan y efectivizan los intereses del conjunto.

Si bien desde afuera pueden dar la impresión de cualquier paraje no indígena de provincia, la relación de los tobas con respecto a esta modalidad de asentamiento ha seguido cursos notoriamente diferentes que el de sus pares "criollos" (como los qom denominan a sus vecinos no indígenas). La pequeña economía ganadera de estos los ha llevado a formar puestos de pequeñas haciendas, esto es, una casa para la residencia familiar, asociada a corrales, establos, huertas, herramientas de trabajo rural y espacio para pastoreo animal, por lo cual los parajes criollos han adquirido una morfología de mayor dispersión espacial y menor interacción entre las unidades domésticas, si se los compara con los tobas. La economía de las familias tobas se ha caracterizado por una gran variabilidad a lo largo del último siglo. Período en el que pasaron de ser cazadores-pescadores-recolectores y horticultores esporádicos a jornaleros en ingenios, obrajes y haciendas de algodón, así como pequeños productores de variedades de huerta, algodón, miel y ganado menor. Últimamente combinan estas labores con empleos públicos en municipios cercanos, en puestos de ordenanzas, maestros y enfermeros o bien beneficiarios de ingresos periódicos tales como pensiones y transferencias monetarias condicionadas (v.g. Asignación Universal por Hijo).

10 Zelda Franceschi y María Cristina Dasso (2010) hablan de un proceso de “parajización” para el caso wichí, tal es la importancia de dicho lugar para la socialidad indígena desde la década de 1980. 
Estas transformaciones han hecho descansar la economía familiar en el rol del líder "lenguaraz", ${ }^{11}$ punto de contacto y traducción con los agentes que demandaron la mano de obra indígena y proporcionaron las compensaciones dinerarias. Esto ha formado un liderazgo bastante estable para los cánones históricos chaqueños (Braunstein y Meichtry, 2008), con una acumulación de conocimientos y contactos en el mundo no indígena que le permite monopolizar la regulación de las transacciones entre las comunidades y los agentes externos. Esta dinámica ha jugado un papel central en la formación de los parajes que hace que las familias se asienten allí donde encuentran el mejor nexo de confianza con los proveedores de ingresos y bienes de primera necesidad. Por supuesto, el prestigio de estos nexos no es intocable y aún se encuentra en gran parte sometido a la tradición de liderazgos sin autoridad de las tierras bajas sudamericanas (Clastres 2008; Sztutman 2012).

Para entender algo más de la formación de estos asentamientos, otro eje a tener en cuenta y que a veces coincide con el de "líder lenguaraz" es el de la iglesia. Hoy en día el evangelio, como los qom denominan a la fe cristiana evangélica, forma parte de la identidad y socialidad indígena. Su rol ha sido, antes que disruptivo, de fortalecimiento cutural, al punto que para los qom ha llegado a ser un importante marcador de identidad que los diferencia de sus vecinos criollos católicos (Wright 2008; Ceriani Cernadas 2005; Miller 1979). Una iglesia con pastores respetados, buena oratoria y una congregación consolidada, es un punto importante para atraer a las personas que quieran vivir en un marco de tranquilidad y sin disquisiciones. La iglesia evangélica como comunidad dirigida por un pastor toba que no se erige en el intermediario entre el creyente y la divinidad, constituye un espacio público de peso para canalizar las necesidades personales y colectivas, en el seno de una socialidad que valora marcadamente la libertad individual (Cordeu 1967: 85 y ss.). Asimismo, la iglesia se convierte en un atractivo de aquellos grupos de música, danza u oradores reconocidos de otros parajes que deseen difundir su arte, lo que a su vez implica un rédito político relevante para la congregación local y sus pastores.

Otro eje de peso que explica el lugar donde se forman estos conglomerados es el acceso a las rutas y caminos que conectan con los pueblos y ciudades donde se localizan los proveedores de alimentos y vestimenta, ${ }^{12}$ servicios médicos, bancarios, energía eléctrica y otros servicios residenciales. Así, encontramos

I 1 Que remplazó al líder cazador y al líder guerrero de siglos anteriores.

12 En los parajes suele haber alguna tienda de productos esenciales, pero son costosos. Por lo general pertenecen a familias criollas que o bien se asientan en el paraje indígena o bien solo tienen el negocio. Las tiendas de tobas no prosperan debido a la expectativa de parientes que esperan acceder a las mercancías al fiado o bien no pagarlas nunca. Lo cual se ubica en el seno de la peculiaridad que adquieren las transferencias y flujos entre parientes. El parentesco y la provisión de alimentos, como luego veremos, es algo más complejo que los derechos y obligaciones nacidas de la consanguinidad. 
parajes, con mayor y con menor conexión con estos puntos. Por lo general, los más alejados ostentan una población con mayores carencias habitacionales y de consumo en general, y es donde las personas aún preservan más prácticas y conocimientos de subsistencia en base a la caza-pesca-recolección. Asimismo, esos son los lugares indicados como los sitios donde viven los chamanes más poderosos. La carencia económica de esos lugares es entendida como símbolo de que el chamanismo practicado allí es más verdadero y poderoso que en otros sitios, ya que sus practicantes no se enriquecen a costa de exigir paga a cambio de curar y eso los vuelve más reconocidos para el resto de la comunidad. Esto hace a estos lugares atractivos para aquellos que quieren iniciarse en tales conocimientos o que su enfermedad requiera la intervención de chamanes calificados.

\section{RESIDENCIA Y PARENTESCO}

En el área de estudio, se contaban hacia el año 2000 unos 15 parajes donde vivían unas 2050 personas, mientras que en la actualidad hay algo más de una veintena donde viven unas 2400 personas. Sin duda, estos asentamientos rebelan el influjo de las nociones hegemónicas de organización del espacio social. Por la dimensión de los lotes asignados para la residencia y la producción, y por la tipología de viviendas que se financian y construyen desde las agencias públicas se infiere que la unidad social que se encuentra en la base de la planificación del ordenamiento territorial gubernamental es la familia nuclear. El proceso de sedentarización y la incorporación de nuevas costumbres residenciales es uno de los aspectos de la colonización que más impactó sobre las antiguas pautas estructuradas en base a la movilidad espacial y cohabitación de familias extendidas. Sin embargo, estos cambios parecen haber impactado más trayendo a la escena a la familia nuclear, que eliminando el papel social de la familia extendida y desestructurando por completo el modo por el cual esta se relaciona con otras. Antes de seguir puede ser útil revisar algunas cualidades del parentesco en la región.

Según la literatura antropológica, la nomenclatura del parentesco de la región no muestra un nivel de definición como en otras áreas que han permitido estudiar los sistemas de parentesco clásicos. Respecto de la filiación no hay consenso de si en el Chaco prevalece una descendencia patrilineal, matrilineal o bilateral, aunque si hay mayor consenso sobre el hecho de que la residencia post-marital es con frecuencia uxorilocal (v.g. Braunstein 1983; Karsten 1932; Métraux 1946a). Tradicionalmente, la unidad social básica parece ser la familia extendida, a partir de la cual se forman otros agregados por la cohabitación de dos o más familias extensas que la literatura llama "banda", y al conjunto de bandas emparentadas por alianza llama "tribu". Con la conquista y la sedentarización, dichos agregados perdieron protagonismo en aras de la 
comunidad asentada en una misma aldea, como principal referente de aglutinamiento social.

Respecto de los tobas en particular, la literatura clásica ha observado que cuando los agregados tradicionales tenían una función social mayor que en la actualidad, las alianzas matrimoniales se caracterizaban por la exogamia de banda y endogamia tribu (Braunstein 1983), pero también se ha encontrado endogamia de banda (Cordeu y de los Ríos 1982; Miller 1979). Y otros hablaron de exogamia de comunidad (Karsten 1932; Miller 1966). Como se ve tampoco hay acuerdo a este respecto y en general ha prevalecido la idea de una tendencia toba de apertura hacia los otros, que contrastaría con un repliegue o endogamia más acentuada entre los wichí (Cordeu y de los Ríos 1982). Una tentativa de establecer líneas comunes del área ha sugerido que, en general, no hay reglas de alianza prescriptivas más que la prohibición de casarse con consanguíneos y la tendencia pragmática de escoger cónyuge en grupos lo más alejados posible para extender las redes de parentesco, o bien en grupos donde un consanguíneo ya ha desposado para cimentar la alianza previa (Bossert, Sendón, y Villar 2012; Braunstein 1983; Miller 1966; Dell'Arciprete 1992).

No obstante, cabe mencionar que recientemente estos trazos generales han recibido un aporte para el caso toba. Sobre la base de una amplia base de información genealógica, teniendo en cuenta varias generaciones y la dispersión geográfica de la localización de las familias extendidas producida por las nuevas formas de asentamientos, se ha observado una marcada preferencia a buscar cónyuges y amantes entre parientes consanguíneos y redoblados - donde otro consanguíneo ya ha desposado - (Tola 2014). Lo que daría cuenta de una tendencia sociológica y genealógica al repliegue en los tobas (Tola 2014), asemejándose así a una de las cualidades más salientes del matrimonio wichí. Entonces, las personas que se consideran parientes entre sí pertenecerán a una misma familia extendida que elabora sus alianzas del modo señalado, y a pesar de que la cohabitación es una situación preferible, por las formas actuales de asentamiento, algunos integrantes de esta familia extensa pueden vivir en diferentes parajes.

Estos apuntes son sumamente importantes para nuestro tema, porque ayudan a entender el rol de la familia extensa en la dinámica al interior y entre los parajes. Sin embargo, vivir en uno de estos parajes fue lo que me permitió tener una imagen más acabada de esto, al observar ¿quiénes se visitan mutuamente? ¿Con qué frecuencia? ¿Con qué motivo? Y ¿qué clase de informaciones y recursos circulan en estas visitas?, se hacía palpable que en todo momento era la familia extensa la que orientaba a las personas en sus circuitos e intercambios cotidianos más frecuentes.

La asistencia entre parientes es considerada una obligación entre los tobas, a la que no se puede eludir bajo pena de ser considerado "mezquino" y quedar 
aislado de los vínculos familiares en el caso de que la conducta se prolongue. Las viviendas diseñadas y destinadas para las familias nucleares se localizan, por lo general, en las cercanías de otras pertenecientes a integrantes de la familia extendida, debido a que todas las personas, en caso de poder, prefieren vivir lo más cerca posible de sus parientes, salvo que el matrimonio, la conveniencia económica u otra situación obligue a residir en otros parajes. Pero el vínculo con la familia extensa se sigue cimentando con visitas esporádicas. Esta dinámica hace que el uso de la vivienda ideada para una familia nuclear quede casi reducido al de espacio dormitorio de la misma, porque en efecto es habitada de distintas formas por otros integrantes de la familia extendida. Los mismos pueden sentarse a comer en cualquiera de las viviendas "asociadas" sin solicitarlo y serán alimentados siempre que lo deseen. Asimismo, cuando hay buena pesca o colecta de frutos del algarrobo (Prosopis alba) y miel silvestre, o se ha realizado una gran compra de alimentos producto de una buena temporada de trabajo, todos estos productos circularán entre las mismas. En suma, en cualquiera de estas casas será normal ver a diario no solo a los habitantes de la misma sino a sus parientes, ya sea comiendo, tomando mate o conversando al lado del fuego.

Por su parte, entre personas que no se consideran parientes raramente se replicarán estos escenarios, sobre todo por el temor latente en los tobas a ser enfermados por sus potenciales enemigos, lo que puede suceder en forma casi inadvertida. ${ }^{13}$ Según la teoría nativa, a veces basta una mirada o la contigüidad de objetos dañinos ${ }^{14}$ con las prendas del destinatario del daño para que se concrete el contagio de propiedades indeseables, que tendrán efectos negativos sobre la salud de la persona. En un paraje grande donde conviven dos o más familias extensas, las dinámicas diarias de cada una de ellas, siguiendo estos trazos descriptos, hacen visible la presencia de circuitos diferentes por los que circulan las personas y los objetos de cada familia extensa. Debido a que dichos circuitos tienen casi nulos puntos de contacto se generan al interior del paraje cuasi subsecciones internas.

A pesar de ello, persiste una cierta articulación entre dichas subsecciones gracias a la figura del líder o dirigente de la comunidad, que a menudo puede ocupar simultáneamente cargos de importancia en la iglesia del paraje y en la asociación civil o personería jurídica del mismo. O bien puede compartir la dirección de alguno de estos cargos con otros líderes de su familia o de otras. Estos espacios junto a la escuela primaria son donde converge el interés y

13 Con el tiempo entendí que "enemigo" es un concepto que no necesariamente se encarna en personas concretas. Pero, su presencia potencial justifica muchas decisiones que la gente toma a diario y explica algunos acontecimientos negativos, como la enfermedad.

14 Tales como cenizas, polvo de hueso u otros objetos pequeños curados por un especialista llamado brujo para dañar. 
demandas comunes de las familias, ya que son los nexos institucionales a partir de los cuales se obtienen recursos estimados por todos, tales como educación formal, donaciones, conocimientos bíblicos de misioneros visitantes, planes de vivienda, gestión de ingresos familiares, etc.

Aunque el compartir alimentos con personas que no son consideradas parientes no es una obligación, como se dijo, en el caso del/de los dirigente/s sí tiene/n la obligación de distribuir, más allá de sus parientes, los recursos que han obtenido gracias al lugar que tienen por representar a toda la comunidad. Por ejemplo, nuevos cargos, insumos, herramientas de trabajo, recursos para vivienda, etc. Por lo general hay un desacuerdo sobre lo que se considera y no se considera como distribuible y ese es casi siempre el disparador de diferendos, que encuentran de nuevo como principales actores implicados a las familias extensas. Un magro resultado en la gestión de recursos comunitarios por parte del líder o una distribución sesgada de los mismos serán interpretados como actos intencionales de "mezquindad", sin importar las justificaciones que puedan ofrecerse. Esta situación, por supuesto, dispara desconfianzas, rumores $\mathrm{y}$, eventualmente, ataques brujeriles que tienen por fin presionar al jefe a repartir o conseguir más recursos. ${ }^{15}$

En este sentido, el repentino adelgazamiento del dirigente de un paraje donde viví, en el año 2016, había sido atribuido a la brujería. Al respecto, un anciano chamán, insatisfecho con el accionar de este líder, me dijo "yo le advertí y le dije [al líder], te vas a quedar flaco, puro hueso, por andar mintiendo a la gente". Carlos Salamanca y Florencia Tola (2002) han propuesto una vinculación entre brujería y guerra en tanto ambas constituyen formas de "predación", al notar que el adelgazamiento que sufre aquel afectado por la brujería es atribuido al hecho de "estar siendo comido" por el brujo. Ante tales temibles efectos, es normal que las partes implicadas en un diferendo traten de evitarse. He visto familias enteras mudarse a otros parajes, e inclusive fundar uno nuevo, luego de conflictos de esta índole. Seguramente, particiones de estas características pueden explicar en parte la notable multiplicación de parajes que se verifica en el territorio qom.

Es cierto que los qom hablan de "la comunidad" para referirse a las familias de un paraje, pero aunque se acuda al término que la legislación y las agencias de promoción usan para referirse al colectivo indígena en abstracto, en tanto titular de derechos, dicho conjunto está lejos de ser homogéneo y estable en el tiempo. Si bien es cierto que, por momentos, la socialidad en esta "comunidad" podría describirse a partir del lenguaje de la convivialidad (Overing y Passes 2000), en tanto arte de disponer relaciones pacíficas, agradables y armónicas, donde lo que prima en los vínculos es la pertenencia y el "compartir"; también

15 Para un análisis de la relación entre brujería y diferenciación socio-económica contemporánea entre los qom $c f$. Gordillo (2006). 
es cierto que, por momentos, la misma podría describirse a partir del lenguaje de la guerra-predación (Clastres 2009; Castro 1992; Fausto 2014), aquí lo que caracteriza las relaciones no es necesariamente la violencia, antes sí la apertura al otro y la incorporación de lo ajeno como sine qua non para la elaboración del sí mismo.

\section{EN EL BOSQUE VIVEN SUS "DUEÑOS"}

Apartándose silenciosamente de las expectativas de las agencias de promoción y activistas ambientales que imaginan a los indígenas rurales integrados a contextos como la chacra, la huerta o el bosque, como se vio, los qom viven en los parajes. Los mismos se encuentran siempre en una porción desbrozada, ecológica y conceptualmente separada del bosque. En las conceptualizaciones nativas del mismo a menudo aparece como opuesto al paraje, ya que este es percibido como un lugar cierto y más seguro si se lo compara con el monte, ríos y pastizales a donde la gente se dirige en busca de leña, presas, frutos, miel y poderes chamánicos. Pero además de esto el bosque presenta azares que se desprenden de encuentros fortuitos con animales peligrosos o del humor y agresividad de la multiplicidad de seres no-humanos que habitan en estos medios.

El monte circundante a las viviendas de los qom, donde se busca leña, raíces y hojas con fines medicinales y los niños juegan, es por lo general el menos riesgoso; más allá de este, hasta para los más experimentados puede resultar peligroso. Los senderos se empiezan a cerrar y cada claro del bosque se parece al anterior. He oído historias de gente que pasó noches enteras perdida y pudo regresar luego de caminar en círculos sin darse cuenta de ello. Incluso en montes cercanos, hay gente que perdió la orientación y encontró la salida en lugares insospechados. Los relatos de estos extravíos abundan en experiencias de adquisición de nuevos poderes, pero también puede resultar seriamente enfermada. ${ }^{16}$ Por ello, los más inexpertos evitan ingresar al monte más espeso salvo que sea extremadamente necesario.

Según mis anfitriones más experimentados, para entrar al bosque no solo es necesario saber cómo eludir las confusiones y las seducciones que deparan algunos no-humanos, sino que también hay que saber "cómo pedir", es decir, cómo despertar la compasión de los "dueños", mediante oraciones y rogativas,

16 En 2016, el abuelo de una niña de 5 años, que sufría de dolores de cabeza y lloraba mucho de noche, me contó que debido a que los médicos no podían sanarla, la llevaron al chamán (pi'oxonaq). Allí la niña le contó que gustaba mucho de ir a una parte del monte cercano a su casa porque allí había un pequeño hombrecillo que la hacía jugar y que la invitaba a ir con él. El chamán recomendó al abuelo observar las huellas del sendero que suele hacer la niña, porque quizás se trate de Huashe, un trickster del monte que atrae y pierde a la gente. Un día el abuelo constató esto, entonces el chamán curó a la niña e intercedió ante Nouet, el dueño del monte, para evitar que Huashe se lleve a la niña. 
para instarlos a dar lo que se necesita (presas, raíces, frutas, conocimientos, poderes, etc.). ${ }^{17}$

Según la experiencia y comentarios de mis interlocutores, al igual que los "parajes", cada monte, laguna, pastizal o río está habitado por un existente no-humano que controla y protege el lugar (el padre, jefe, o dueño del lugar como normalmente se lo llama), quien vive junto a las especies vegetales o animales que protege y con las cuales mantiene un vínculo familiar: éstas son "sus hijos" ${ }^{18}$. De hecho, la mayoría de los topónimos que remiten a dichos lugares refieren a las personas no-humanas o a las especies que viven allí. "Este monte es la casa de Pianne", "esa laguna es la casa de Vicaiq cañi" " o "en esa laguna vive Nanatauaxai" son algunos ejemplos. Como ya dijimos anteriormente, Pianne es el nombre de una persona no-humana. Vicaiq hace referencia a una especie de pez que abunda en la laguna, cuyo "dueño" puede salir y seducir a los humanos, para luego sumergirse y hacerlos entrar en la laguna. Finalmente, Nanatauaxai es el nombre de una mujer humana seducida y devenida no-humana.

Los qom llaman en general a estos existentes shiỹaxaua. Según Tola (2012) este es un término que alude a un tipo de entidad con capacidad de reflexión e intención, semejante al término castellano de "persona". Debido a que shij̃ axaua aparece en contextos que aluden tanto a humanos como a no-humanos se deduce que, desde el punto de vista indígena, la conciencia y la capacidad volitiva no son características exclusivas de los humanos, al menos conceptualmente. Por ejemplo, dicho término puede ser aplicado a existentes no-humanos, como los dueños, los espíritus auxiliares de los chamanes, los espíritus de los muertos o los de los humanos por nacer. Asimismo, al igual que los humanos, cada shiz̃axaua no-humano tiene cualidades particulares, humores y pasiones singulares. Mientras que algunos son más generosos y bondadosos, otros son mezquinos y agresivos.

Una breve referencia a los rasgos centrales de la cosmología de la región puede ayudar a apreciar mejor estos pasajes. Vale la pena remarcar que, para algunos autores (Tola 2012), dicho campo para algunos se presenta como una verdadera "socio-cosmología", debido a la imbricación que presentan los sucesos y las acciones en el mundo humano y extra humano desde la perspectiva nativa.

17 Para una casuística del "arte de pedir" como eje de las relaciones entre humanos, y entre estos y no-humanos, en Chaco y Mesoamérica, ver Dapuez y Tola (2016). Ver también el género de la oratoria en el arte verbal qom en Messineo (2014).

18 Para un análisis de la relación social y de posesión de los “dueños" con sus protegidos en Amazonía ver Fausto (2008), y en Chaco, ver Tola (2010). 


\section{LA FORMA DEL MUNDO}

En el Chaco indígena es difundida la idea de que el universo circundante se constituye de tres estratos perfectamente reconocibles: el cielo, la tierra y las profundidades. En los mitos de algunos pueblos, a su vez el cielo y el subsuelo pueden tener más de una capa. En el caso toba, cada capa es el cielo de la de abajo y la siguiente es el subsuelo de la anterior (Palavecino 1961: 94). Los humanos viven en el estrato del medio, la tierra, pero todos los estratos y sus capas están habitados por vida social semejante a la de la tierra. Tanto las alturas como las profundidades son la morada de espíritus que controlan fenómenos atmosféricos, especies animales y vegetales, habilidades, conocimientos, etc. Quienes visitan a los humanos a diario y pueden ser visitados por estos por intermedio de aquellos que ostentan capacidades chamánicas (interespecíficas), quienes a su vez llegan en búsqueda de poderes para sanar o ayudar a los demás, o bien rescatar a humanos que fueron capturados por aquellos espíritus (Cordeu 1969: 75 y ss.; Idoyaga Molina 1995: 42; Métraux 1946b: 24-26; Lehmann-Nitsche 1924: 182-184; Tola 2012; López y Altman 2017; Wright 2008; Miller 1979).

Este mundo por lo general cobra una forma escalonada si se lo considera en relación al poder. Hay seres más poderosos que otros, que son considerados jefes, dueños o padres por los que siguen en la escala, su personal, empleados, auxiliares o tutelados. Según algunas versiones, en la cúspide se encuentran sol, luna, las estrellas Pléyades y otros seres de carácter uránico por medio de cuya capacidad y accionar se generó el mundo tal como lo conocemos hoy. ${ }^{19}$ Por debajo de estos se encuentran otros seres, subordinados, encargados de cuidar diferentes dominios animales, vegetales, geográficos, atmosféricos y otros no fácilmente clasificables tales como la noche o donde moran los espíritus de los muertos.

Desde el punto de vista indígena, estos dueños y sus tutelados mantienen entre si un vínculo semejante al de un padre con sus hijos, vínculo que a menudo deriva al que hay entre un jefe y sus seguidores. Cada dueño posee una casa en un punto determinado del cielo, monte o ríos, desde donde

19 Las teorías indígenas más notorias acerca de cómo los humanos terminaron viviendo en la tierra hablan de una inversión de la antigua tierra, que ahora es el cielo, donde vivían los humanos del tiempo primordial junto a un personaje poderoso (de carácter uránico), quien enojado por la suciedad de estos, llevo la primera tierra para el cielo y creó una nueva tierra para los humanos, luego se retiró al cielo - vide el ciclo de Nilatáj entre los wichí tewokleley, v.g. Braunstein (1974) -; Dapitchí entre los tobas orientales y pilagá (Tomasini 1976) y K'ata entre los tobas occidentales (Cordeu 1969: 125-126) forman ciclos similares. Encontramos también otro protagonista, diferente al ser uránico, en la constitución de la tierra y del mundo como lo conocemos hoy, los cataclismos (Cordeu 1969: 127-137). De algún modo, los mismos están presentes en los ciclos antes mencionados, ya que Nilatáj, Dapitchí o K'ata invierten el mundo luego que la primera tierra 'tiembla' a causa de la aglomeración y suciedad humanas, más precisamente su defecación. 
custodian a sus protegidos, en el caso de los animales sus dueños cuentan con una suerte de "corral" cerca de su casa. En las mismas pueden vivir integrados a estas familias, el espíritu de personas humanas (o la fuerza que da vitalidad y voluntad a los humanos) que en paseos nocturnos pudo ser dañada o haber sido extraviada y cautiva por algún dueño. Entonces los chamanes cantarán y visitarán al mismo en su casa para intentar recuperar el espíritu perdido. De ese modo se configuran estas relaciones socio-cósmicas.

Estas imágenes del cosmos dejan un cuadro con partes bien marcadas entre las cuales se organiza la vida, que podría sintetizarse del siguiente modo:

\begin{tabular}{|c|c|c|c|}
\hline Estratos & Arriba & Intermedio & Abajo \\
\hline \multirow{3}{*}{ Ámbitos } & cielo & tierra & profundidades \\
\hline & montaña & $\begin{array}{l}\text { superficie de estero, } \\
\text { río, laguna }\end{array}$ & interior de agua \\
\hline & copa de los árboles & monte, campo & subsuelo \\
\hline \multirow{3}{*}{ Habitantes } & ser uránico & $\begin{array}{l}\text { dueños de monte } \\
\text { y pastizal }\end{array}$ & $\begin{array}{l}\text { salamanca, arco iris } \\
\text { (serpiente mítica) }\end{array}$ \\
\hline & $\begin{array}{l}\text { luna, sol, pléyades, } \\
\text { vía láctea y otros } \\
\text { cuerpos celestes }\end{array}$ & $\begin{array}{l}\text { dueños de especies } \\
\text { animales, vegetales } \\
\text { y mieles }\end{array}$ & $\begin{array}{l}\text { dueños de los peces } \\
\text { y animales de costumbre } \\
\text { acuática }\end{array}$ \\
\hline & $\begin{array}{l}\text { dueños de los vientos } \\
\text { y de la lluvia } \\
\text { y las tormentas }\end{array}$ & $\begin{array}{l}\text { tricksters, animales, } \\
\text { plantas, humanos }\end{array}$ & muertos \\
\hline
\end{tabular}

\section{APUNTES LINGÜÍSTICOS SOBRE LA NOCIÓN QOM DE "POSESIÓN"}

Según Hansjakob Seiler (1983), la "posesión lingüística” consiste en la relación entre dos entidades, un poseedor típicamente animado y más específicamente humano y un poseído que puede ser más o menos animado. Semánticamente, el dominio de la "posesión" es definido por el autor como biocultural, es decir, como una relación entre un ser humano y sus parientes, sus partes del cuerpo, sus pertenencias materiales y sus productos culturales e intelectuales. Sintácticamente, la posesión implica una relación entre dos nombres, un agente y un paciente, si el verbo interviene entre ambos es sólo para hacer explícita dicha relación. ${ }^{20}$

De acuerdo a Cristina Messineo (2000) y María Belén Carpio (2012), especialistas en lengua qom oriental y occidental respectivamente, la "posesión" - en el caso de esta lengua - clasifica nombres poseídos inalienables, por un 
lado, y nombres poseídos alienables, por otro. Sin embargo, ésta no se presenta como una división excluyente, sino más bien como un gradiente que va desde posesiones más inalienables hacia otras más alienables, pudiendo haber misceláneas. En términos generales, esta distinción se basa en la posibilidad de separar - o no - los poseedores de las entidades poseídas, o bien en la mayor o menor proximidad conceptual entre los nombres involucrados. Esto último implica que mientras más inalienable es la posesión, mayor dependencia tiene con su poseedor - y viceversa - . Asimismo, ello tiene un correlato a nivel formal dado que a mayor inalienabilidad, menor es la distancia (menos palabras o afijos) con la que lingüísticamente se expresa la relación entre poseedor y poseído.

Siguiendo esta distinción, podemos citar los siguientes como casos de nombres inalienables: cabeza, corazón, sangre, grano, arruga, madre, casa. Para ser poseídos estos nombres sintácticamente solo reciben una partícula al inicio, por ejemplo: $l m a$ ' (su casa) donde la $l$ inicial es marcador de posesión de la tercera persona del singular, mientras que $m a^{\prime}$ es el objeto poseído. Por otra parte, enumeramos algunos casos de nombres alienables: pescado, fuego, arma,

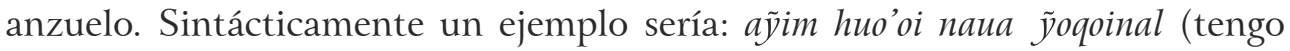

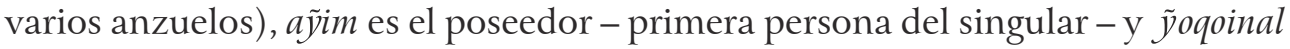
es el objeto poseído. Asimismo, estas autoras notan que mientras hay nombres que pueden recibir marcas posesivas, como los anteriormente citados, existen otros que no pueden recibir marca de posesión bajo ninguna forma, como, por ejemplo, noche, luna, tierra y jaguar (excepto en el contexto del relato mítico y respecto de su "dueño" no-humano). Sin embargo, eventualmente, un nombre originalmente no pasible de ser poseído puede pasar a recibir marca de posesión por medio de la construcción atributiva y-o'xot o lamaxat. Por ejemplo, el nombre "tierra" que en principio no puede ser poseído, puede pasar a serlo cuando se usa junto al nombre y-o'xot o lamaxat, significando entonces "mi tierra". De todos modos, las construcciones atributivas elaboran una posesión que se encuentra en el polo más alienable del continuum, es decir dentro de los nombres con mayor distancia conceptual y separabilidad semántica con respecto a su poseedor. ${ }^{21}$

Es importante notar que cuando mis interlocutores desean referir al "territorio qom" como tierra de su propiedad según la ley, dicen "na aleu 'qom lalamaxat" (esta tierra es propiedad de los qom). Y, cuando se refieren a partes específicas del territorio, como un monte o una laguna donde se sabe vive un shiỹaxaua individualizado dicen, por ejemplo, "ne'ena aviaq l'enaxat Pianne lma" " (ese monte es la casa de Pianne). Esta construcción también se usa para referir a los lugares donde abunda una especie - jolo lma' (la casa del chancho del

21 Montani (2017) ha hecho una observación semejante respecto de "la tierra" en el caso de la lengua wichí, del Chaco argentino. 
monte) - y para señalar específicamente la vivienda donde mora una familia o una persona (Roberto lma', lo que quiere decir "la casa de Roberto"). Recordemos que la construcción lma' está dentro de las formas de posesión más inalienables, mientras que lamaxat está dentro de las posesiones más alienables.

Volviendo a la distinción entre posesiones inalienables y alienables, podríamos decir que un monte o una laguna determinados, por más de que se encuentren catastralmente dentro de la propiedad de los qom tienen, en términos nativos, un mayor grado de dependencia y control respecto de sus "dueños" no-humanos que respecto de sus titulares humanos. Esto se debe a que dichos "dueños" son quienes viven allí, cuidan y administran sus recursos. Es notorio que cuando los qom aprendieron las connotaciones de la palabra en castellano "dueño", la asociaron rápidamente al vínculo de los no-humanos con sus posesiones, antes que al vínculo de los humanos con las suyas. Del mismo modo, "tierra" en tanto área de propiedad de un humano, se encontraría dentro de las posesiones más alienables. En este sentido, habría una mayor independencia entre el poseedor (humano) y poseído (tierra), y una mayor distancia conceptual, así como un menor grado de control por parte de su poseedor. Quizás esto permita entender la facilidad con la que los qom se desprenden temporariamente de los lugares donde moran cuando es necesario procurar sitios donde haya menos "envidia" y amenazas brujeriles, o bien una mayor generosidad o respuesta a sus necesidades.

\section{A MODO DE CIERRE:}

\section{EQUIVOCACIONES Y TRAYECTORIAS “TRANSVERSALES”}

Se ha visto que más allá de la planificación gubernamental y las transformaciones socioeconómicas operadas en esta población, los parajes son considerados por los qom su morada, donde se expresa y desarrolla actualmente su vida social. En los parajes los niños aprenden a hablar qom l'aqtaqa (lengua qom) y se educan, las familias pueden conseguir un lote y vivienda para vivir, una congregación a la que unirse, así como el apoyo de los dirigentes para tener acceso a empleos o la gestión de ayuda social. Asimismo, la dinámica establecida por la circulación de personas y objetos, la tendencia a construir las viviendas en las cercanías de la parentela o las mudanzas producto de diferendos tienen un impacto tangible en la morfología de los parajes. Por ello, no deben vérselos solo como ordenamientos residenciales externamente impuestos.

A su vez, más allá de las tentativas gubernamentales de hacer del espacio de la ex-reserva un lugar donde producir o un ambiente natural al cual los indígenas debieran incorporarse por medio de relaciones productivas y armónicas, la percepción qom es que los distintos espacios del bosque están habitados por personas no-humanas con intenciones y pasiones propias. Lo cual puede significar graves peligros, pero también preciadas recompensas como conocimientos 
y poderes chamánicos. No obstante la notable oposición que emerge entre paraje:humano:certeza::bosque:no-humano:incerteza, hay un punto de contacto en el hecho de que en ambos espacios prevalecen las mismas pautas "sociales", la generosidad y la mezquindad (o agresividad) que configuran la atracción o la expulsión-evasión de los lugares.

Entonces, desde el punto de vista nativo, amén de la diversidad, lo que hay en parajes y bosque son generosidades y mezquindades-agresiones, es decir potencias que pueden aumentar, o bien disminuir las capacidades de las personas, al afectar sus voluntades y sus cuerpos. Por ejemplo, conocimientos, objetos de poder, alimentos, presas, palabras de sanación o nombres son algunas cosas que pueden tornar más fuerte y sana a una persona. A la inversa, alimentos "curados" para dañar, objetos-bichos que enferman, sustracción de poderes de la persona, confusión y pérdida del interés en algo o alguien, son cosas con las que también uno se puede encontrar al transitar por estos lugares. Por lo general, esto se manifiesta corporalmente, por medio de marcas visibles o del estado de salud del organismo. Todas estas prácticas que hemos descripto pueden entenderse en el marco de la idea, extendida en las tierras bajas sudamericanas, de que tanto las relaciones de parentesco (Tola 2012; Brightman, Grotti y Fausto 2016) como de dominio (Brightman, Grotti y Fausto 2016) "se hacen" con la cohabitación y con el compartir alimentos y fluidos, con el dar nombres, marcas o prendas, entre otras, ${ }^{22}$ lo cual configura no solo relaciones (de parentesco o dominio), sino también cuerpos.

De la misma manera, la generosidad, por ejemplo, en tanto cualidad del vínculo padre-hijo, dueño-protegido y poderoso-carente, también se elabora, "se hace". Si la equivocación es el modo de comunicación entre posiciones de un mundo compuesto por diferentes perspectivas (Castro 2004, 2010), la traducción de puntos de vista implicada aquí no pretende colocar los conceptos del otro plenamente en los términos de uno, como si hubiera un mundo unívoco; antes si dejarse afectar, asumiendo que hay una diferencia irreductible y que es ésta la que posibilita la relación y no la que la impide. En este marco, "hacer la generosidad" o "tornar compasivos" a los otros (sean jefes humanos o dueños no-humanos) es habitar el equívoco, es transitar un mundo de múltiples puntos de vista, donde comunicar es hacer saber de las necesidades del carente y sus efectos, lograr la compasión del otro, pero por sobre todo aumentar las capacidades del que pide. Sin embargo, los afectos no son siempre positivos, en un mundo de múltiples perspectivas e intenciones, éstas no pueden ser completamente controladas e, inclusive, pueden volverse en contra de la persona.

En este contexto de fuerzas que se despliegan en un espacio sin dirección ni límites precisos, donde solo es posible avanzar a tientas, "equivocando", 
resultan anti-intuitivas las exigencias de los agentes estatales que solicitan a los indígenas "establecer relaciones (productivas o de cuidado ambiental) más estables" ahora que tienen "la propiedad de la tierra". ${ }^{23}$ Incluso, hablar de ello en qom l'aqtaqa ${ }^{24}$ implica nociones de no inherencia, de alienabilidad, y, en definitiva, de flujos. Como se mostró, resulta notable que las únicas áreas del territorio que pueden nombrarse como "posesiones inalienables", donde prevalecen relaciones de cuidado y protección en el tiempo, son los montes, lagunas o sectores de un río que pertenecen a un dueño no-humano.

En suma, se ha visto que antes que un punto de llegada en materia de derecho indígena territorial, el caso en análisis revela vertiginosas tensiones y cambios. La flexibilidad y gradientes que se visualizan en la lengua verifican una correspondencia notoria en el modo como transcurren las relaciones qom, tanto en el espacio del paraje como en el bosque. Sin embargo, las fluctuaciones, inconstancia y ambigüedades indígenas en estos tránsitos no deberían verse como producto de la apatía, incapacidad, incomprensión o "tendencia natural nómade". Estos circuitos configurados por las trayectorias de personas y objetos en el espacio, que describí en base a la etnografía qom, resuenan con un ejercicio de tránsitos "transversales" que como tales exceden la tentativa de captura del "segmento" políticas de desarrollo (poniéndolo en términos de Deleuze y Guattari, 2015). A partir de dichas nociones se podría establecer un diálogo fructífero con los materiales qom, sin embargo, no me detendré en esta discusión en este momento dado que excede el objetivo de este trabajo. Más allá de estas discusiones, es bueno notar que hay derechos que deben ser respetados en el actual estado de cosas. Solo resta preguntarse qué sucedería si somos consecuentes con todas las implicancias de las afecciones que los conceptos qom aquí revisados provocan a nuestras nociones de territorio, derecho y propiedad.

23 Se podría decir que no es tan sorprendente que a los qom ello les parezca anti-intuitivo, ya que en términos estrictamente sociológicos y filosóficos la propiedad es una relación social y esta es estable solo jurídica o virtualmente, pero de hecho es energía del trabajo en movimiento (Marx 1968) o flujos capturados por la sobrecodificación del aparato de Estado, tal como dirían Deleuze y Guattari (2015). 24 Recordemos que para decir "tierra propiedad de los qom" se dice, "na aleu' qom lalamaxat", apelando al uso de posesión alienable. 


\section{BIBLIOGRAFÍA}

BOSSERT, Federico, Pablo SENDÓn, y Diego VILLAR, 2012, "Introducción: relevancia y actualidad de los estudios de parentesco en antropología”, El Parentesco: Textos Fundamentales. Buenos Aires, Biblos, 14-77.

BRAUNSTEIN, José, 1974, "Dominios y jerarquías en la cosmovision de los matacos Tewokleley”, Scripta Ethnologica, 2 (II): 7-30.

BRAUNSTEIN, José, 1983, Algunos Rasgos de la Organización Social de los Indígenas del Gran Chaco. Buenos Aires, Universidad de Buenos Aires, Facultad de Filosofía y Letras, Instituto de Ciencias Antropológicas.

BRAUNSTEIN, José, y Norma MEICHTRY, 2008, Liderazgo, Representatividad y Control Social en el Gran Chaco. Corrientes, EUDENE.

BRAUNSTEIN, José, y Elmer MILLER, 1999, “Ethnohistorical introduction”, en Elmer Miller (comp.), Peoples of the Gran Chaco. Westport, CT, Bergin \& Garvey, 1-22.

BRIGHTMAN, Marc, Vanessa Elisa GROTTI, y Carlos FAUSTO (comps.), 2016, Ownership and Nurture: Studies in Native Amazonian Property Relations. Nueva York, Berghahn Books.

CARPIO, María Belén, 2012, Fonología y Morfosintaxis de la Lengua Hablada por Grupos Tobas en el Oeste de Formosa (Argentina). Múnich, Lincom Europa Academic Publishers.

CASTRO, Eduardo Viveiros de, 1992, From the Enemy's Point of View: Humanity and Divinity in an Amazonian Society. Chicago, The University of Chicago Press.

CASTRO, Eduardo Viveiros de, 1996, "Os pronomes cosmológicos e o perspectivismo ameríndio", Mana, 2 (2): 115-44.

CASTRO, Eduardo Viveiros de, 2004, "Perspectival anthropology and the method of controlled equivocation", Tipiti: Journal of the Society for the Anthropology of Lowland South America, 2: (1), 3-22, disponible en: < http://digitalcommons.trinity.edu/tipiti/vol2/ iss $1 / 1>$ (última consulta en junio de 2020).

CASTRO, Eduardo Viveiros de, 2010, Metafisicas Canibales: Líneas de Antropología Postestructural. Buenos Aires y Madrid, Katz.

CENTRO DE ESTUDIOS LEGAlES Y SOCIALES, 1991, "El grito toba de Colonia Teuco: el reclamo aborigen de tierras más importante del siglo”, Cuadernos del CELS, 5 (2): 3-53.

CERIANI CERNADAS, César, 2005, "El movimiento del evangelio entre los tobas del Chaco argentino: una revisión histórica y etnográfica”, en Guerrero Jiménez, De Indio a Hermano: Pentecostalismo Indígena en América Latina. Iquique (Chile), Ediciones Campus, 11 1-170.

CLASTRES, Pierre, 2008, La Sociedad contra el Estado. La Plata, Terramar.

ClASTReS, Pierre, 2009, Arqueología de la Violencia: La Guerra en las Sociedades Primitivas. Buenos Aires, Fondo de Cultura Económica.

CORDEU, Edgardo, 1967, “Cambio cultural y configuración ocupacional en una comunidad toba. Miraflores, Chaco”, Informe Preliminar 12 J. Argentina, Comisión Nacional del Río Bermejo.

CORDEU, Edgardo, 1969, "Aproximación al horizonte mítico de los tobas", Runa, 12: 67-176.

CORDEU, Edgardo, y DE LOS RÍOS, Miguel, 1982, "Un enfoque estructural de las variaciones socioculturales de los cazadores-recolectores del Gran Chaco", Suplemento Antropológico, 1: 131-95.

CORDEU, Edgardo, y Alejandra SIFFREDI, 1971, De la Algarroba al Algodón: Movimientos Milenaristas del Chaco Argentino. Buenos Aires, Juárez. 
DAPUEZ, Andrés, y Florencia TOLA (comps.), 2016, El Arte de Pedir: Antropología de Dueños y Suplicantes. Villa María (Córdoba), Eduvim.

DELEUZE, Gilles, y Félix GUATTARI, 2015, Mil Mesetas: Capitalismo y Esquizofrenia. Valencia, Pre-Textos.

DELl'ARCIPRETE, Ana, 1992, “Terminología de parentesco pilagá”, Hacia Una Nueva Carta Étnica del Gran Chaco, 4: 9-19.

ESCOBAR, Arturo, 1999, "Antropología y desarrollo", Maguaré, 14: 42-73.

FAUSTO, Carlos, 2008, "Donos demais: maestria e domínio na Amazônia”, Mana, 14: 329. $-366$.

FAUSTO, Carlos, 2014, Inimigos Fiéis: História, Guerra e Xamanismo na Amazônia. São Paulo, Edusp.

FAUSTO, Carlos, y Michael HECKENBERGER (comps.), 2007, Time and Memory in Indigenous Amazonia: Anthropological Perspectives. Gainesville, University Press of Florida.

FELD, Steven, y Keith BASSO (comps.), 1996, Senses of Place. Santa Fe, NM, School of American Research Press.

FRANCESCHI, Zelda Alice, y Maria Cristina DASSO, 2010, Etno-grafías: La Escritura como Testimonio entre los Wichí. Buenos Aires, Corregidor.

GORDILlO, Gastón, 2006, En el Gran Chaco: Antropologías e Historias. Buenos Aires, Prometeo. GUPTA, Akhil, y James FERGUSON, 1992, “Beyond 'culture': space, identity, and the politics of difference”, Cultural Anthropology, 7 (1): 6-23.

IDOYAGA MOLINA, Anatilde, 1995, Modos de Clasificación de la Cultura Pilagá. Buenos Aires, Centro Argentino de Etnología Americana.

INGOLD, Tim, 1986, The Appropriation of Nature: Essays on Human Ecology and Social Relations. Manchester, Manchester University Press.

IÑIGO CARRERA, Nicolás, 2010, Génesis, Formación y Crisis del Capitalismo en el Chaco, 1870-1970. Salta, Universidad Nacional de Salta.

KARSTEN, Rafael, 1932, Indian Tribes of the Argentine and Bolivian Chaco: Ethnological Studies. Helsingfors, Akad. Buchh. [u. a.].

LAFOne QUeVEDO, Samuel A., 1893, Arte de la Lengua Toba. La Plata, Museo de La Plata.

LEHMANN-NITSCHE, Roberto, 1924, "Mitología sudamericana X: la astronomía de los tobas [segunda parte]", Revista del Museo de La Plata, 28: 181-209.

LÉVI-STRAUSS, Claude, 1973, "Les discontinuités culturelles et le développement économique et social”, en Claude Lévi-Strauss, Anthropologie Structurale Deux. París, Plon.

LÉVI-STRAuss, Claude, 1988, El Pensamiento Salvaje. México, DF, Fondo de Cultura Económica.

LÉVI-STRAUSS, Claude, 1995, The Story of Lynx. Chicago, The University of Chicago Press. LÓPEZ, Alejandro, y Augustina ALTMAN, 2017, “The Chaco skies: a socio-cultural history of power relations", Religion and Society: Advances in Research, 8: 62-78.

MARX, Karl, 1968, Manuscritos Económicos e Filosóficos de 1844. México, DF, Grijalbo.

MARX, Karl, 2012, El Capital. México, DF, Fondo de Cultura Económica.

MESSINEO, Cristina, 2014, Arte Verbal Qom: Consejos, Rogativas y Relatos de El Espinillo (Chaco). Buenos Aires, Rumbo Sur/Ethnographica.

MESSINEO, Cristina, 2000, Estudio del Toba Hablado en la Provincia del Chaco (Argentina): Aspectos Gramaticales y Discursivos. Buenos Aires, Universidad de Buenos Aires.

MÉTRAUX, Alfred, 1946a, Ethnography of the Chaco. Washington, DC, US Government Printing Office. 
MÉTRAUX, Alfred, 1946b, Myths of the Toba and Pilagá Indians of the Gran Chaco. Filadelfia, American Folklore Society.

MILLER, Elmer, 1966, “Toba kin terms”, Ethnology, 5 (2): 194-201.

MILlER, Elmer, 1979, Los Tobas Argentinos. Armonía y Disonancia en una Sociedad. México, DF, Siglo Veintiuno.

MILler, Elmer (comp.), 1999, Peoples of the Gran Chaco. Westport, CT, Bergin \& Garvey.

MONTANI, Rodrigo Matías, 2017, El Mundo de las Cosas entre los Wichís del Gran Chaco: Un Estudio Etnolingüístico. Cochabamba, Bolivia, Instituto Latinoamericano de Misionología ILAMIS.

NIKLISON, José Elías, 1916, "Investigación en los territorios federales del Chaco y Formosa", Boletín del Departamento Nacional de Trabajo, 34.

OVERING, Joanna, y Alan PASSES, 2000, The Anthropology of Love and Anger: The Aesthetics of Conviviality in Native Amazonia. Londres y Nueva York, Routledge.

PALAVECINO, Enrique, 1961, "Algo sobre el pensamiento cosmológico de los indígenas chaqueños", Cuadernos del Instituto Nacional de Antropología y Pensamiento Latinoamericano, 2 (0): 93-95.

RANCIÈRE, Jacques, 2004, "Política, identificación, subjetivación”, Metapolítica, 8 (36): 26-32.

SAHLINS, Marshall David, 2011 , "What kinship is (part two)", Journal of the Royal Anthropological Institute, 17 (2): 227-242.

SALAMANCA, Carlos, y Florencia C. TOLA, 2002, "La brujería como discurso político entre los tobas del Chaco argentino", Desacatos, 9: 96-116.

SEILER, Hansjakob, 1983, "Possesivity, subject and object", Studies in Language, 7.

SZTUTMAN, Renato, 2012, O Profeta e o Principal. São Paulo, Edusp.

TOLA, Florencia, 2010, "Maîtres, chamanes et amants: Quelques réflexions sur la conception toba d'agentivité", Ateliers du LESC, 34, disponible en < http://ateliers.revues.org/8 538_> (última consulta en junio de 2020).

TOLA, Florencia, 2012, Yo no Estoy Solo en Mi Cuerpo. Buenos Aires, Biblos/Culturalia.

TOLA, Florencia, 2014. "Esposos y amantes consanguíneos entre los tobas (qom) del Gran Chaco", Journal de la Société des Américanistes, 100 (1): 131-61.

TOLA, Florencia, 2016, "Introducción: una historia más que humana", en Florencia Tola y Valentín Suarez, El Teatro Chaqueño de las Crueldades: Memoria Qom de la Violencia y el Poder. Buenos Aires y Resistencia, Asociación Civil Rumbo Sur, Conicet-IIGHI, 23-46.

TOMASINI, Alfredo, 1976, "Dapitchi, un alto dios uranico de los Toba y Pilaga", Scripta Ethnologica, 4: 69-87.

TRINCHERO, Hugo, Daniel PICCININI, y Gastón GORDILlO, 1992, Capitalismo y Grupos Indígenas en el Chaco Centro-Occidental (Salta y Formosa)/I. Buenos Aires, Centro Editor de América Latina.

VIOLA, Andreu (comp.), 2000, Antropología del Desarrollo: Teoría y Estudios Etnográficos en América Latina. Barcelona, Paidós.

WRIGHT, Pablo, 2008, Ser en el Sueño: Crónicas de Historia y Vida Toba. Buenos Aires, Biblos/ Culturalia. 